\title{
BMJ
}

\section{Stopping smokeless tobacco with varenicline: randomised double blind placebo controlled trial}

\author{
Karl Fagerström, director, ${ }^{1}$ Hans Gilljam, professor, ${ }^{2}$ Michael Metcalfe, senior medical manager, ${ }^{3}$ Serena \\ Tonstad, head consultant, ${ }^{4}$ Michael Messig, primary care statistics ${ }^{5}$
}

${ }^{1}$ Smokers Information Centre, Fagerström Consulting AB, Berga Alle 1, 25452 Helsingborg, Sweden ${ }^{2}$ Department of Public Health Sciences, Karolinska Institutet, Postbox 17 070, 10462

Stockholm, Sweden

${ }^{3}$ Pfizer, Tadworth, Surrey KT20 7NS, UK

${ }^{4}$ Oslo University Hospital, Ullevå Department of Preventive Cardiology, Oslo, Norway

${ }^{5}$ Pfizer, New York, NY 10017, USA Correspondence to: K Fagerström Karl.fagerstrom@swipnet.se

Cite this as: BMJ 2010;341:c6549 doi:10.1136/bmj.c6549

\section{ABSTRACT}

Objective To assess the efficacy and safety of varenicline (a licensed cigarette smoking cessation aid) in helping users of smokeless tobacco to quit.

Design Double blind, placebo controlled, parallel group, multicentre, randomised controlled trial.

Setting Medical clinics (mostly primary care) in Norway and Sweden.

Participants Men and women aged $\geq 18$ who used smokeless tobacco at least eight times a day, with no abstinence period over three months within one year before screening, who wanted to quit all tobacco use. Participants were excluded if they used any other form of tobacco (except smokeless tobacco) or medication to stop smoking within three months of screening or had any pre-existing medical or psychiatric condition.

Interventions Varenicline $1 \mathrm{mg}$ twice daily (titrated during the first week) or placebo for 12 weeks, with 14 weeks' follow-up after treatment.

Main outcome measures The primary end point was the four week continuous abstinence rate at the end of treatment (weeks 9-12) confirmed with cotinine concentration. A secondary end point was continuous abstinence rate for weeks 9-26. Safety and tolerability were also evaluated.

Results 431 participants (213 varenicline; 218 placebo) were randomised and received at least one dose of study drug. Participants' demographics and baseline use of smokeless tobacco were similar (89\% (189) and 90\% (196), respectively, were men; mean age in both groups was 43.9; participants used smokeless tobacco products about 15 times a day, and about $80 \%$ first used smokeless tobacco within 30 minutes after awakening). Continuous abstinence rate at week 9-12 was higher in the varenicline group than the placebo group (59\% (125) $\checkmark 39 \%$ (85); relative risk $1.60,95 \%$ confidence interval 1.32 to 1.87 , P $<0.001$; risk difference $20 \%$; number needed to treat 5). The advantage of varenicline over placebo persisted through 14 weeks of follow-up (continuous abstinence rate at week 9-26 was 45\% (95) $v$ $34 \%$ (73); relative risk $1.42,1.08$ to $1.79, \mathrm{P}=0.012$; risk difference $11 \%$; number needed to treat 9 ). The most common adverse events in the varenicline group compared with the placebo group were nausea (35\% (74) $v 6 \%(14))$, fatigue (10\% (22) v 7\% (15)), headache $(10 \%$
(22) v 9\% (20)), and sleep disorder (10\% (22) v 7\% (15)). Few adverse events led to discontinuation of treatment (9\% (19) and 4\% (9), respectively), and serious adverse events occurred in two (1\%) and three (1\%) participants, respectively.

Conclusion Varenicline can help people to give up smokeless tobacco and has an acceptable safety profile. The response rate in the placebo group in this study was high, suggesting a population less resistant to treatment than smokers.

Trial Registration NCT00717093.

\section{INTRODUCTION}

The use of smokeless tobacco products is increasing in many countries. In Scandinavia the use of smokeless tobacco, specifically snus (a moist tobacco product, consumed by placing it under the upper lip), is well established. In Swedish men the prevalence of use is higher than that of smoking (19\% v 11\% in 2008), ${ }^{12}$ and in Norway a considerable proportion (32\%) of young men (aged 16-35) use snus every day. ${ }^{3}$ Despite the high prevalence of use of smokeless tobacco in Scandinavia, the largest market in Western countries is in the United States, where about $5 \%$ of adult men and $13 \%$ of male adolescents are daily users of smokeless tobacco, and the trend is increasing. ${ }^{4-6}$

Smokeless tobacco is often considered less harmful than smoking, ${ }^{7}$ and this could explain why in Sweden it is used by nearly $30 \%$ of male smokers trying to quit. ${ }^{8}$ According to the American Cancer Society, however, up to half of users of smokeless tobacco would like to quit in the next year. ${ }^{9}$ While there are several hundred studies on smoking cessation that have documented the efficacy of pharmacotherapy and behavioural support, there are far fewer studies on cessation of smokeless tobacco, perhaps because of the widely held belief that it is less harmful than smoking. Most of the published studies have evaluated brief behavioural methods. In a Cochrane meta-analysis of 12 studies from 2007, behavioural interventions were found to be effective. ${ }^{10}$ In contrast, pharmacological treatments have not proved effective. In an analysis of eight trials of pharmacological treatment, the 2007 Cochrane review found that pharmacotherapy had no effect: two trials used bupropion (odds ratio 0.86, 95\% 
confidence interval 0.59 to $1.63, v$ controls), two trials used nicotine gum $(0.98,0.59$ to 1.63$)$, and four trials used nicotine patches $(1.16,0.88$ to 1.54$) .{ }^{10} \mathrm{~A}$ more recent randomised placebo controlled trial showed a non-significant trend towards efficacy with a $4 \mathrm{mg}$ nicotine lozenge $(1.5,0.7$ to 2.1$) .{ }^{11}$

Varenicline is a specific partial agonist of the $\alpha 4 \beta 2$ nicotinic acetylcholine receptor, ${ }^{12}$ which is effective in increasing abstinence rates among cigarette smokers. ${ }^{13}$ Varenicline could be expected to help users quit smokeless tobacco because of its mechanism of action. It can stimulate the release of sufficient dopamine to reduce craving and withdrawal while simultaneously acting as a partial antagonist, thereby blocking the binding of nicotine to the receptors-and consequently the reinforcing effects of nicotine intake ${ }^{14}$ —and reducing the likelihood of a full relapse. Studies comparing users of smokeless tobacco with smokers have shown that the two forms of tobacco consumption are associated with similar concentrations of nicotine in the blood and similar or slightly higher concentrations of cotinine in users of smokeless tobacco. ${ }^{1516} \mathrm{We}$ evaluated the efficacy and safety of varenicline compared with placebo for the cessation of use of smokeless tobacco.

\section{METHODS}

\section{Study design}

From August 2008 to July 2009, we recruited daily users of smokeless tobacco into this double blind, placebo controlled, randomised, multicentre, parallel group clinical trial in Norway (seven sites: one at a specialist smoking cessation clinic; six in primary care) and Sweden (nine sites: one at a specialist smoking cessation clinic; five in primary care; three in secondary care hospitals). Participants were recruited almost exclusively through newspaper advertising. Our primary objective was to examine the efficacy of varenicline $1 \mathrm{mg}$ twice daily compared with placebo for cessation of smokeless tobacco after 12 weeks of treatment. Secondary objectives included evaluations of efficacy for a further 14 weeks of follow-up after treatment and safety through the treatment period and four weeks after the last dose.

\section{Participants}

To be included, men and women aged $\geq 18$ had to be using smokeless tobacco containing nicotine (at least eight times a day during the previous year with no period of abstinence in the three months before screening) but be motivated to stop use of all tobacco products. They had to be prepared to adhere to the protocol and provide informed consent. Women of childbearing age were included if they were not pregnant or breast feeding and had agreed to practise effective contraception for at least one month before and for the duration of the trial.

Exclusion criteria included use of any other nicotine containing products other than smokeless tobacco during the previous three months (participants' exhaled carbon monoxide had to be $\leq 10 \mathrm{ppm}$ at screening); use of varenicline, bupropion, or nicotine replacement treatment within the previous three months; use of any other investigational drug from 30 days before to 30 days after the study; history of drug or alcohol misuse within the past 12 months; or any serious psychiatric or medical condition (for example, depression) or treatment with any drugs that might interfere with the outcome of the trial or interpretation of safety or efficacy evaluations.

\section{Interventions}

Eligible participants were randomised to one of two parallel treatment arms in a 1:1 ratio (varenicline:placebo) by using a telephone interactive voice response system (IVRS). Participant identification numbers were allocated in the numerical order in which participants were accepted to the study. Study investigators contacted the IVRS to obtain participants' identification numbers and double blinded randomised allocations. The dose of varenicline was titrated up during the first week $(0.5 \mathrm{mg}$ once daily for three days, then $0.5 \mathrm{mg}$ twice daily for four days), followed by $1 \mathrm{mg}$ twice daily through week 12 . Participants randomised to placebo followed the same dosing regimen with matching placebo tablets. Participants were instructed to take tablets orally with water. Compliance with treatment was documented at all study visits and at the end of treatment visit during week 12 .

Participants were instructed to set a target quit date during days 8 to 28 after initiation of treatment. Because of the lack of guidelines for behavioural support or counselling for cessation of smokeless tobacco, participants were offered brief behavioural support or counselling at the discretion of the investigator and in accordance with local standard practice. In most cases participants were given simple advice and helpful tips, together with discussion of any topics or concerns raised by the participants. The potential health risks of smokeless tobacco were discussed only in response to a query from a participant.

\section{Assessments}

Baseline assessments occurred during the first visit and included assessment of demography, medical history, concomitant use of drugs, physical examination, blood pressure, heart rate, and body weight. The latter was reassessed at weeks 12 and 26. We obtained each participant's history of smoking and use of smokeless tobacco and used a modified Fagerström test for nicotine dependence (modified for use of smokeless tobacco, see appendix 1 on bmj.com). Each question had an associated score, and the total score achieved by the participant determined their level of nicotine dependency.

Use of smokeless tobacco was assessed weekly at weeks 9-12 and again at week 26 with a self completion questionnaire, modified from one designed for and implemented in previous varenicline studies to collect information about nicotine use. Abstinence from 


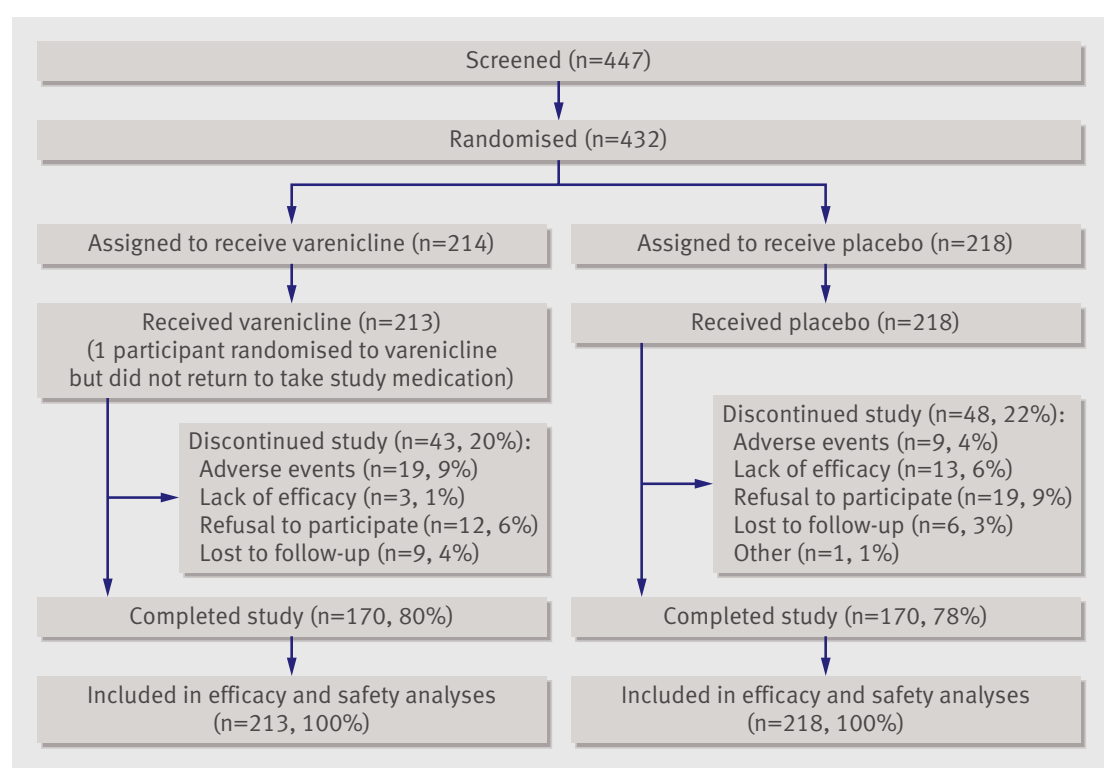

Fig 1 Flow of participants through study

smokeless tobacco was confirmed by measurement of salivary cotinine at baseline and reassessed weekly from weeks 9-12 and at week 26. Participants whose cotinine concentration was $>15 \mathrm{ng} / \mathrm{ml}$ at any given time point were classified as non-responders (using smokeless tobacco or another form of nicotine containing product) for the corresponding end point, even if they reported abstinence from tobacco.

To assess safety and tolerability of varenicline in smokeless tobacco users, investigators recorded all adverse events, either observed or reported by participants, including details on severity (mild, moderate, or severe), as well as the investigators' expert medical opinions on the relation of the adverse events to the study treatment. These adverse events were coded using the Medical Dictionary for Regulatory Activities (MedDRA). Adverse events were recorded from the time of the first dose of study treatment up to 28 days after the last dose was taken. For all adverse events, the investigators determined the outcome of the adverse event and whether any specific adverse events met the criteria for classification as a serious adverse event. A serious adverse event was defined as any adverse event that was life threatening; caused death; resulted in new admission to hospital or prolonged an existing stay; led to a persistent or severe disability or incapacity; resulted in a congenital anomaly or birth defect; or required medical or surgical intervention to prevent one of these outcomes listed. Serious adverse events could also include any adverse event that the sponsor or investigators considered serious enough to be classified as such. If any adverse events or their sequelae persisted, follow-up was required until resolution or stabilisation occurred at a level acceptable to the investigator and sponsor.

Participants could withdraw from the study themselves or at the discretion of the investigators or sponsor (for example, for safety, behavioural, or administrative reasons). Whenever possible, every effort was made to document participants' outcomes such as abstinence, reasons for withdrawal, and safety status. If a participant withdrew from the trial and also withdrew consent for disclosure of future information, no further evaluations were performed, and no additional data were collected.

\section{Outcome measures}

The primary efficacy end point was the continuous abstinence rate over the last four weeks of study treatment (weeks 9-12), defined as proportion of participants who reported abstaining from smokeless tobacco during the indicated period confirmed by cotinine measurements during clinic visits. Secondary end points included long term continuous abstinence rate (weeks 9-26), seven day point prevalence of abstinence (defined as the proportion of participants who abstained from smokeless tobacco for the seven days before the end of treatment (week 12) and the end of the study (week 26)), and the safety and tolerability of varenicline versus placebo for 12 weeks of treatment.

\section{Statistical analysis}

Analyses included all participants who took at least one dose of study medication. Participants who discontinued the study were classified as still using smokeless tobacco for the remainder of the study. Efficacy end points were analysed with logistic regression models with terms for study centre and treatment group. Significance tests for the treatment comparison (varenicline $v$ placebo) were performed at the two sided 0.05 level, and the $95 \%$ confidence intervals were two sided.

The study was designed to have at least $90 \%$ power to detect a difference between varenicline and placebo, assuming a response rate for the four week continuous abstinence rate of 0.35 and 0.20 , respectively (relative risk 1.75), with a two sided significance of 0.05 .

We conducted exploratory analyses to assess whether treatment effects varied according to baseline salivary cotinine concentration and baseline score on a modified Fagerström test. We used logistic regression models to analyse the four week and long term continuous abstinence rates with additional terms for baseline salivary cotinine concentration or baseline modified Fagerström test score and their interaction with treatment. The cotinine scores were defined as $1=<361 \mathrm{ng} / \mathrm{ml}, 2=361-499 \mathrm{ng} / \mathrm{ml}$, and $3=\geq 500 \mathrm{ng} / \mathrm{ml}$ (the upper limit of quantification for salivary cotinine concentrations was $500 \mathrm{ng} / \mathrm{ml}$ ). Cotinine scores were assigned because the upper level of quantification was $500 \mathrm{ng} / \mathrm{ml}$ and almost $60 \%$ of participants had baseline cotinine values in excess of this. The scores were chosen to represent a ratio of about 1:1:2 of participants and were tested for simple linear relations to the outcomes. Possible scores on the modified Fagerström test ranged from 1 to 10 (observed scores ranged from 3 to 10). We determined Spearman's non-parametric rank 
Table 1|Demographic characteristics of participants at baseline according to allocation to varenicline or placebo for help in cessation of use of smokeless tobacco products

\begin{tabular}{|c|c|c|}
\hline & Varenicline $(n=213)$ & Placebo $(n=218)$ \\
\hline \multicolumn{3}{|l|}{ Physical characteristics } \\
\hline No (\%) of men & $189(89)$ & $196(90)$ \\
\hline Mean (SD) age (years) & $43.9(12.0)$ & $43.9(12.0)$ \\
\hline Mean (SD) weight $(\mathrm{kg})$ & $86.0(13.8)$ & $86.3(14.3)$ \\
\hline No (\%) white & 211 (99) & $217(100)$ \\
\hline \multicolumn{3}{|l|}{ History of use of smokeless tobacco } \\
\hline \multicolumn{3}{|l|}{ Age at first use (years): } \\
\hline Mean (SD) & $22.9(11.6)$ & $21.7(10.2)$ \\
\hline Range & $11-66$ & $6-60$ \\
\hline \multicolumn{3}{|l|}{ No of years of use: } \\
\hline Mean (SD) & $20.3(11.0)$ & $21.7(11.8)$ \\
\hline Range & $1-45$ & $1-50$ \\
\hline \multicolumn{3}{|l|}{ Portions used per day: } \\
\hline Mean (SD) & $15.4(5.8)$ & $15.9(7.7)$ \\
\hline Range & $8-40$ & $8-80$ \\
\hline \multicolumn{3}{|l|}{ Longest period of abstinence in past year (days): } \\
\hline Mean (SD) & $3.1(11.4)$ & $5.5(13.7)$ \\
\hline Range & $0-90$ & $0-90$ \\
\hline \multicolumn{3}{|l|}{ No of previous serious quit attempts: } \\
\hline Mean (SD) & $1.72(2.67)$ & $2.16(5.04)$ \\
\hline Range & $0-15$ & $0-50$ \\
\hline No (\%) who had never previously attempted to quit & $90(42)$ & $77(35)$ \\
\hline Mean (SD) modified Fagerström test score* & $7.5(1.6)$ & $7.6(1.7)$ \\
\hline No (\%) of former smokers & $104(48)$ & $104(49)$ \\
\hline
\end{tabular}

correlation for the baseline modified Fagerström test total scores versus the baseline salivary cotinine scores.

\section{RESULTS}

Of 447 participants screened, 432 were randomised to receive varenicline $(\mathrm{n}=214$; one participant did not take any varenicline) or placebo $(n=218) ; 170$ participants in each treatment group completed the study (fig 1).

\section{Baseline and demographic characteristics}

Demographic characteristics were comparable between treatment groups; more than $88 \%$ of participants were men, with an average age of 43.9 , and weighing on average over $86 \mathrm{~kg}$ (table 1). Participants averaged over 20 years of use of smokeless tobacco, and at baseline used it about 15-16 times a day. In total, $58 \%$ of the varenicline group and $65 \%$ of the placebo group had attempted to quit previously, with average longest periods of abstinence of 3.1 days (varenicline) and 5.5 days (placebo) in the year before the study (table 1). Around 48\% were former smokers.

Users of smokeless tobacco in both groups seemed to have high levels of nicotine dependence, as indicated by high baseline salivary cotinine concentrations (300-499 ng/ml cotinine in 113/399 (28\%); $\geq 500 \mathrm{ng} / \mathrm{ml}$ cotinine in 234/399 (59\%); the upper limit of quantification for salivary cotinine concentrations was
$500 \mathrm{ng} / \mathrm{ml}$, so we could not determine the maximum level or the frequency distribution above $500 \mathrm{ng} / \mathrm{ml}$ ); the short time ( $\leq 30$ minutes) to first use of smokeless tobacco after waking $(171 / 213(80 \%)$ in the varenicline group and $173 / 218(79 \%)$ in the placebo group); and the mean (SD) scores on the Fagerström test at baseline (7.5 (1.6) and 7.6 (1.7), respectively; table 1).

\section{Efficacy}

\section{Primary efficacy end point}

The continuous abstinence rate at the end of treatment (weeks 9-12) was significantly higher in the varenicline group than in the placebo group (59\% (125) v 39\% (85); risk difference 20\%; number needed to treat 5) (fig 2).

\section{Secondary efficacy end points}

Continuous abstinence rates were also significantly higher in the long term (weeks 9-26) in the varenicline group than in the placebo group (45\% (95) v 34\% (73); risk difference $11 \%$; number needed to treat 9 ) than in the placebo group (fig 2).

When we compared former smokers with never smokers in both treatment groups combined, continuous abstinence rates at week 9-26 were significantly higher for former smokers than for never smokers (44\% (94) v 34\% (73); risk difference 10\%; number needed to treat 10 ; relative risk $1.18,1.02$ to 1.33 , $\mathrm{P}=0.031)$.

Among non-responders (participants who self reported use of nicotine containing products or with salivary cotinine concentrations $>15 \mathrm{ng} / \mathrm{ml}$, or both) at weeks $9-12$, seven participants (three in the varenicline group ( $3 \%$ of non-responders) and four in the placebo group (3\% of non-responders)) started smoking cigarettes, pipes, or cigars. Similarly, at weeks 9-26 there were 14 non-responders (seven $(6 \%)$ and seven $(5 \%)$, respectively) who started smoking cigarettes, pipes, or cigars.

Consistent with the higher continuous abstinence rate with varenicline at the end of treatment, seven

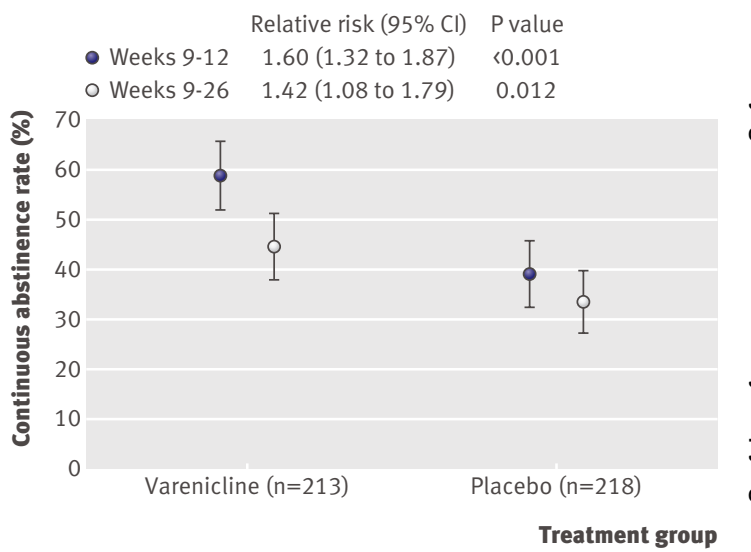

Fig 2 | Continuous abstinence rates with varenicline versus placebo achieved at end of treatment. Continuous abstinence rates analysed with logistic regression models with terms for study centre and treatment group 


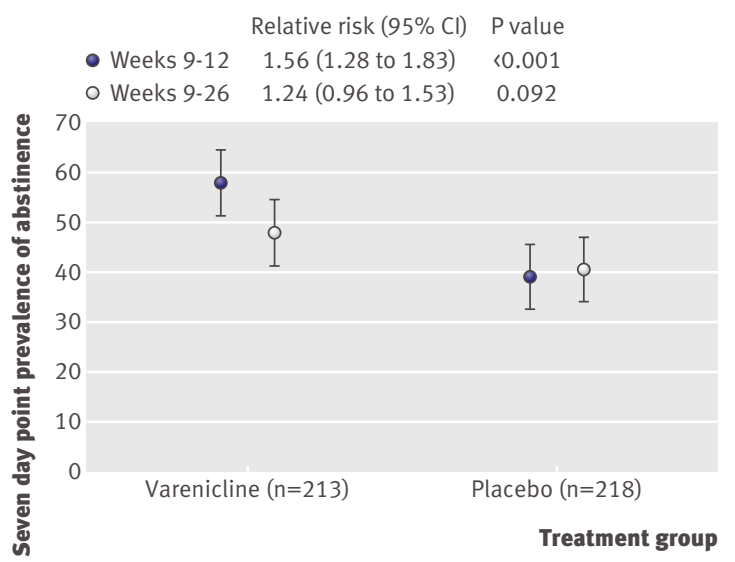

Fig 3 | Seven day point prevalence of abstinence for varenicline and placebo at end of treatment. Point prevalences of abstinence analysed with logistic regression models with terms for study centre and treatment group

day point abstinence rates were also higher at week 12 in the varenicline group than the placebo group (58\% (124) $v 39 \%$ (85); risk difference $19 \%$; number needed to treat 5) (fig 3). Though week 26 seven day point prevalence of abstinence was numerically larger with varenicline than with placebo $(48 \%$ (102) v 40\% (87); risk difference $18 \%$; number needed to treat 13 ) (fig 3), this difference was not significant.

There were no significant differences in treatment effect across centres, although there were 16 study centres and the number of participants in some centres was low. There were no significant effects of treatment by country.

We performed post hoc analyses for continuous abstinence rates and seven day point rates of abstinence because at baseline more participants in the varenicline group had previously attempted to quit smokeless tobacco than those in the placebo group (42\% v 35\%, respectively). Adjustment for whether participants had previously attempted to quit smokeless tobacco or not did not substantially alter the results reported for the a priori analyses above or the conclusions drawn from them. Varenicline was significantly better than placebo with respect to continuous abstinence rates at weeks 9-12 (relative risk 1.58, 95\% confidence interval 1.31 to $1.85, \mathrm{P}<0.001)$ and at weeks 9$26(1.41,1.08$ to $1.77, \mathrm{P}=0.014)$, and the seven day point abstinence rates at week $12(1.57,1.29$ to 1.84 , $\mathrm{P}<0.001)$. Seven day point abstinence rates at week 26 were not significantly different $(1.23,0.96$ to 1.52 , $\mathrm{P}=0.096)$.

As expected from the literature, the two strongest predictors of nicotine dependence-cotinine scores and Fagerström test scores ${ }^{1718}$-were correlated at baseline $(r=0.22 ; \mathrm{P}<0.001)$. When we examined the continuous abstinence rates at weeks 12 and 26, however, we found that neither baseline cotinine nor baseline Fagerström test scores were predictive of outcome (see appendix 2 on bmj.com). In non-responders at weeks $9-12$, median salivary cotinine concentrations at week 12 were lower in the varenicline group (114 $\mathrm{ng} / \mathrm{ml}$ ) than in the placebo group $(307 \mathrm{ng} / \mathrm{ml})$, suggesting less nicotine use in the varenicline group, though these differences were not significant $(\mathrm{P}=0.193)$ because of large variability in cotinine concentrations.

\section{Safety and tolerability}

Table 2 shows the most commonly reported adverse events ( $\geq 5 \%$ incidence in either group). Of these adverse events, the incidence of nausea (35\% v 6\% in placebo group), headache $(10 \% v 9 \%)$, fatigue $(10 \% v$ $7 \%)$, and sleep disorder $(10 \% v 7 \%)$ was at least $10 \%$ in the varenicline group. Concerning neuropsychiatric adverse events, only sleep disorder (10\% v 7\%), abnormal dreams $(8 \% v 1 \%)$, and insomnia $(6 \% v 3 \%)$ were higher with varenicline than with placebo (table 2).

Overall, five participants reported six serious adverse events (two participants had three serious adverse events in the varenicline group; three participants had three serious adverse events in the placebo group). In the placebo group, one participant developed colon cancer, one ruptured an Achilles tendon, and one experienced cardiac failure. None of these was thought to be related to treatment. In the varenicline group, one participant experienced moderate

Table $2 \mid$ Adverse events during treatment (all causes) and discontinuation of treatment because of adverse events. Figures are numbers (percentages) of participants

\begin{tabular}{|c|c|c|}
\hline Adverse events & $\begin{array}{l}\text { Varenicline } \\
\qquad(n=213)\end{array}$ & $\begin{array}{l}\text { Placebo } \\
(n=218)\end{array}$ \\
\hline Occurrence of any adverse event & $168(79)$ & $126(58)$ \\
\hline $\begin{array}{l}\text { Dose reductions or temporary } \\
\text { withdrawal }\end{array}$ & $17(8)$ & $12(6)$ \\
\hline Permanent discontinuations & $19(9)$ & $9(4)$ \\
\hline $\begin{array}{l}\text { Occurrence of serious adverse } \\
\text { events }\end{array}$ & $2(1)$ & $3(1)$ \\
\hline
\end{tabular}

Most commonly reported adverse events ( $\geq 5 \%$ in either treatment group):

\begin{tabular}{lcc}
\hline \multicolumn{4}{l}{ Gastrointestinal disorders } & $11(5)$ & $5(2)$ \\
\hline Abdominal pain & $10(5)$ & $11(5)$ \\
\hline Diarrhoea & $18(9)$ & $7(3)$ \\
\hline Flatulence & $74(35)$ & $14(6)$ \\
\hline Nausea & $22(10)$ & $15(7)$ \\
\hline General disorders and administration site conditions: & $9(4)$ \\
\hline Fatigue & $11(5)$ & \\
\hline Irritability & $12(6)$ & \\
\hline Infections and infestations & $20(9)$ \\
\hline Nasopharyngitis & $22(10)$ & $15(7)$ \\
\hline Nervous system disorders & $3(1)$ \\
\hline Headache & $6(3)$ \\
\hline Reported neuropsychiatric adverse events (all frequencies): \\
\hline Sleep disorder & $17(8)$ & $3(1)$ \\
\hline Abnormal dreams & $13(6)$ & $3(1)$ \\
\hline Insomnia & $4(2)$ & $4(2)$ \\
\hline Nightmare & $4(2)$ & \\
\hline Depressed mood & $2(1)$ & \\
\hline Restlessness & & \\
\hline Depression & $(1)$ & \\
\hline
\end{tabular}


postoperative haemorrhage considered unrelated to the study drug and one experienced two serious adverse events of a loss of consciousness and a resultant traffic incident. This latter participant was a man aged 56 with a two year history of hypertension who was also taking candesartan and amlodipine. He took varenicline for 56 days, and he had stopped using smokeless tobacco. Varenicline treatment was discontinued on day 56 because he was experiencing sleep disorder (including insomnia and somnolence), and two days later he experienced a short loss of consciousness while driving, which resulted in a traffic incident. $\mathrm{He}$ recovered the same day and underwent carotid Doppler ultrasonography five days later, with normal results. The investigator judged the event of loss of consciousness as related to study medication and the traffic incident as related to the loss of consciousness. At the time of the loss of consciousness, however, the plasma concentration of varenicline would have been relatively low because its half life is 24.8 hours. ${ }^{19}$

There were few dose reductions and temporary discontinuations ( $8 \%$ in varenicline group $v 6 \%$ in placebo group) or permanent discontinuations (9\% $v$ v $4 \%$ ) because of adverse events (table 2).

\section{DISCUSSION}

In people using smokeless tobacco products, varenicline resulted in significantly higher rates of continuous abstinence in the last four weeks of treatment and after a further 14 weeks' follow-up after treatment. The seven day point prevalence of abstinence was significantly higher in the varenicline group than the placebo group, although by week 26 the difference between the groups was no longer significant. The most common adverse event in the varenicline group was nausea, which is consistent with the trials of varenicline for smoking cessation. ${ }^{20-24}$ Neuropsychiatric adverse events occurred at the same rate in both treatment groups, with the exception of sleep disorder, abnormal dreams, and insomnia, which are well known side effects associated with varenicline, and are in accordance with a pooled safety analysis of 10 varenicline trials for smoking cessation. ${ }^{25}$ There were few dose reductions or temporary or permanent discontinuations from study drugs, suggesting acceptable tolerability.

Response rates in both groups were higher than those seen previously in corresponding studies of smokeless tobacco and higher than those observed in trials of varenicline for smoking cessation. ${ }^{2021}$ The high quit rate in our placebo group could reflect a high motivation to quit among all participants, especially as we offered limited behavioural support. Participants were recruited almost exclusively through newspaper advertising, and, as they volunteered for the study, their motivation was high. Previous studies, however, have used the same advertisement recruitment method for trials of varenicline for smoking cessation but found lower response rates with placebo. ${ }^{2627}$ Indeed, full recruitment of participants to our trial took only five months, which was much faster than the anticipated eight months, suggesting that there is an unmet clinical need for cessation interventions among users of smokeless tobacco. In addition, the participants in this trial might have been less resistant to cessation than corresponding populations of smokers, who have long been under pressure to quit. For example, a lower proportion of the population in our trial had previously attempted to quit smokeless tobacco compared with the history of previous attempts to quit smoking among the populations of previous trials of varenicline in the West. ${ }^{202123}$

Alternatively, the motivation to quit could be lower for smokeless tobacco than for smoking because of the perception that smokeless tobacco is less harmful. About half of the study population were former smokers and their quit rates at 26 weeks were exceptionally high at $44 \%$ overall. In our trial, the smaller differential treatment effect compared with smoking cessation trials could be because of the high placebo response rate, which could suggest lower dependence on nicotine, despite the observed high nicotine dependence as measured by the modified Fagerström test and salivary cotinine concentrations.

The nicotine dependence in users of smokeless tobacco might have different characteristics compared with the nicotine dependence of smokers. For example, in our trial, despite evidence of high nicotine dependence in the study population, the success rates in both groups-even in the placebo group-were high. It should also be noted that salivary cotinine measurement in smokeless tobacco users might not reflect the same relation to nicotine metabolism in smokers because some nicotine is swallowed, undergoes first pass metabolism in the liver, and is immediately converted to cotinine. ${ }^{28}$ Furthermore, cotinine concentrations and Fagerström test scores did not predict outcome, which is contrary to findings in the smoking cessation literature. ${ }^{1718}$ Because the modified Fagerström test we used is a novel assessment, however, there are no comparisons available in the literature at this time.

\section{Strengths and limitations}

As with all studies, there were some potential limitations with this trial. Varenicline is currently not licensed for smokeless tobacco cessation, and more studies with longer follow-up might be needed to evaluate longer term efficacy. In future studies, the use of more support in the form of behavioural interventions, for example, with dental examinations, ${ }^{29}$ could be of interest. The modified Fagerström test was developed by the originator of the test for smokers (K Fagerström) but has not yet been validated, and further studies evaluating the utility of this test in measuring nicotine dependence among smokeless tobacco users are warranted. In addition, participants were almost exclusively Norwegian or Swedish, most were men, and all used a specific form of smokeless tobacco-namely, snus-so the results might not generalise to other settings or to users of different types of smokeless tobacco 


\section{WHAT IS ALREADY KNOWN ON THIS TOPIC}

The use of oral smokeless tobacco is prevalent in some areas

Current cessation options have focused on brief behavioural interventions

Varenicline has known efficacy among smokers trying to quit

\section{WHAT THIS STUDY ADDS}

Varenicline is more effective than placebo in smokeless tobacco users and has an acceptable safety profile

Participants treated with varenicline were significantly more likely to be abstinent at the end of six months
1 Ministry of Health and Social Affairs in Sweden and Swedish National Institute of Public Health. Results from the National Health Interview Survey. Health on equal terms, 2008-living habits. Ministry of Health and Social Affairs in Sweden and Swedish National Institute of Public Health, 2008.

2 Fiore MC, Jaén CR, Baker TB, Bailey WC, Benowitz NL, Curry SJ, et al. Clinical practice guideline. Treating tobacco use and dependence: 2008 update. US Department of Health and Human Services: Public Health Service, 2008.

3 Lund KE, Tefre EM, Amundsen A, Nordlund S. [Cigarette smoking, use of snuff and other risk behaviour among students.] Tidsskr Nor Laegeforen 2008;128:1808-11.

4 Centers for Disease Control and Prevention. Use of smokeless tobacco among adults-United States, 1991. MMWR Morb Mortal Wkly Rep 1993;42:263-6.

5 Centers for Disease Control and Prevention. Smoking and tobacco use: national youth tobacco survey (NYTS), 2006. NYTS Data and Documentation, 2006.

6 Eaton DK, Kann L, Kinchen S, Shanklin S, Ross J, Hawkins J, et al. Youth risk behavior surveillance-United States, 2007. MMWR Surveill Summ 2008;57:1-131.

products-for example, spit (or chewing) tobacco With regard to the form of smokeless tobacco, however, the primary addictive component of all products is nicotine so the results would probably be replicated in other studies of other forms. Also, the participants of this trial were all physically and psychologically healthy.

\section{Conclusions}

Varenicline seems to be effective for smokeless tobacco cessation and has an acceptable safety and tolerability profile. As varenicline has proved significant efficacy for smoking cessation, it is possible that it might be suitable for treating nicotine dependence in general, thus providing a useful new aid for the cessation of smokeless tobacco products. As the motivation among users to quit was high in this study, it seems likely that there is an urgent need to provide more support and encouragement to smokeless tobacco users who would like to quit.

We thank Abegale Templar, of UBC Scientific Solutions, for editorial assistance in the form of proof reading, collation of reviewers' comments, formatting the manuscript for submission, preparation of figures and tables, and formatting of references. This editorial assistance was funded by Pfizer.

Contributors: KF and MMet participated in the design of the study. KF, ST, and $\mathrm{HG}$ participated in the collection of data. MMes was involved in data analysis. All authors were involved in interpretation of data, drafting the article, reviewing the article for important intellectual content, and the decision to submit the article for publication. KF, ST, and $\mathrm{HG}$ are independent from the funder of the study. All authors had full access to all of the data (including statistical reports and tables) in the study and take responsibility for the integrity of the data and the accuracy of the data analysis. MMet is guarantor

Funding: This work was supported by Pfizer. KF, HG, and ST did not receive any financial support with respect to the writing or development of this manuscript.

Role of the study sponsor: Pfizer, the study sponsor, was involved in study design; in the collection, analysis, and interpretation of data; in the writing of the report; and in the decision to submit the article for publication.

Competing interests: All authors have completed the Unified Competing Interest form at www.icmje.org/coi_discolsure.pdf (available on request from the corresponding author) and declare: the institutions of ST and HG received support from Pfizer for the clinical trial; KF, ST, and HG have specified relationships with Pfizer, who might have an interest in the submitted work; MMet and MMes are employees of, and stockholders in, Pfizer

Ethical approval: This study was approved by the institutional review boards and independent ethics committees and all participants gave written informed consent

Data sharing: No additional data available.
Scientific Committee on Emerging and Newly-Identified Health Risks (SCENIHR). Scientific opinion on the health effects of smokeless tobacco products. 2008. http://ec.europa.eu/health/archive/ ph_risk/committees/04_scenihr/docs/scenihr_0_013.pdf.

8 Gilljam H, Galanti MR. Role of snus (oral moist snuff) in smoking cessation and smoking reduction in Sweden. Addiction 2003;98:1183-9.

9 American Cancer Society. Smokeless tobacco and how to quit. 2009. www.cancer.org/docroot/PED/content/ PED_10_13X_Quitting_Smokeless_Tobacco.asp.

10 Ebbert JO, Montori V, Vickers KS, Erwin PC, Dale LC, Stead LF. Interventions for smokeless tobacco use cessation. Cochrane Database Syst Rev 2007;4:CD004306.

11 Ebbert JO, Severson HH, Croghan IT, Danaher BG, Schroeder DR. A randomized clinical trial of nicotine lozenge for smokeless tobacco use. Nicotine Tob Res 2009;11:1415-23.

12 Coe JW, Brooks PR, Vetelino MG, Wirtz MC, Arnold EP, Huang J, et al. Varenicline: an alpha4beta2 nicotinic receptor partial agonist for smoking cessation. J Med Chem 2005;48:3474-7.

13 Cahill K, Stead LF, Lancaster T. Nicotine receptor partial agonists for smoking cessation. Cochrane Database Syst Rev 2008;3:CD006103.

14 Rollema H, Chambers LK, Coe JW, Glowa J, Hurst RS, Lebel LA, et al. Pharmacological profile of the $\alpha 4 \beta 2$ nicotinic acetylcholine receptor partial agonist varenicline, an effective smoking cessation aid. Neuropharmacology 2007;52:985-94.

15 Gritz ER, Baer-Weiss V, Benowitz NL, Van Vunakis H, Jarvik ME. Plasma nicotine and cotinine concentrations in habitual smokeless tobacco users. Clin Pharmacol Ther 1981;30:201-9.

16 Holm H, Jarvis M), Russell MA, Feyerabend C. Nicotine intake and dependence in Swedish snuff takers. Psychopharmacology (Berl) 1992;108:507-11.

17 Ferguson JA, Patten CA, Schroeder DR, Offord KP, Eberman KM, Hurt RD. Predictors of 6-month tobacco abstinence among 1224 cigarette smokers treated for nicotine dependence. Addict Behav 2003;28:1203-18.

18 Harris KJ, Okuyemi KS, Catley D, Mayo MS, Ge B, Ahluwalia JS. Predictors of smoking cessation among African-Americans enrolled in a randomized controlled trial of bupropion. Prev Med 2004;38:498-502.

19 Faessel HM, Gibbs MA, Clark DJ, Rohrbacher K, Stolar M, Burstein AH. Multiple-dose pharmacokinetics of the selective nicotinic receptor partial agonist, varenicline, in healthy smokers. J Clin Pharmacol 2006;46:1439-48.

20 Gonzales D, Rennard SI, Nides M, Oncken C, Azoulay S, Billing CB, et al. Varenicline, an $\alpha 4 \beta 2$ nicotinic acetylcholine receptor partial agonist, vs sustained-release bupropion and placebo for smoking cessation: a randomized controlled trial. JAMA 2006;296:47-55.

21 Jorenby DE, Hays JT, Rigotti NA, Azoulay S, Watsky EJ, Williams KE, et al. Efficacy of varenicline, an $\alpha 4 \beta 2$ nicotinic acetylcholine receptor partial agonist, vs placebo or sustained-release bupropion for smoking cessation: a randomized controlled trial. JAMA 2006;296:56-63.

22 Nakamura M, Oshima A, Fujimoto Y, Maruyama N, Ishibashi T, Reeves KR. Efficacy and tolerability of varenicline, an a4ß2 nicotinic acetylcholine receptor partial agonist, in a 12-week, randomized, placebo-controlled, dose-response study with 40-week follow-up for smoking cessation in Japanese smokers. Clin Ther 2007;29:1040-56

23 Rigotti NA, Pipe AL, Benowitz NL, Arteaga C, Garza D, Tonstad S. Efficacy and safety of varenicline for smoking cessation in patients with cardiovascular disease: a randomized trial. Circulation 2010;121:221-9. 
24 Tsai ST, Cho HJ, Cheng HS, Kim CH, Hsueh KC, Billing CB Jr, et al. A randomized, placebo-controlled trial of varenicline, a selective $\alpha 4 \beta 2$ nicotinic acetylcholine receptor partial agonist, as a new therapy for smoking cessation in Asian smokers. Clin Ther 2007;29:1027-39.

25 Tonstad S, Davies S, Flammer M, Russ C, Hughes J. Psychiatric adverse events in randomized, double-blind, placebo-controlled clinical trials of varenicline: a pooled analysis. Drug Saf 2010;33:289-301.

26 Gonzales D, Rennard SI, Nides M, Oncken C, Azoulay S, Billing CB, et al. Varenicline, an alpha4beta2 nicotinic acetylcholine receptor partial agonist, vs sustained-release bupropion and placebo for smoking cessation: a randomized controlled trial. JAMA 2006;296:47-55.
27 Jorenby DE, Hays JT, Rigotti NA, Azoulay S, Watsky EJ, Williams KE, et al. Efficacy of varenicline, an alpha4beta2 nicotinic acetylcholine receptor partial agonist, vs placebo or sustained-release bupropion for smoking cessation: a randomized controlled trial. JAMA 2006;296:56-63.

28 Benowitz NL, Jacob P 3rd, Savanapridi C. Determinants of nicotine intake while chewing nicotine polacrilex gum. Clin Pharmacol Ther 1987;41:467-73.

29 Carr AB, Ebbert JO. Interventions for tobacco cessation in the dental setting. Cochrane Database Syst Rev 2006;1:CD005084.

Accepted: 17 September 2010

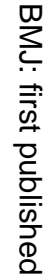

क

$\overrightarrow{0}$ 